\title{
Prevalencia del mobbing en las y los trabajadores de la industria maquiladora en Ciudad Juárez
}

\section{Prevalence of Mobbing in Workers of the Maquiladora Industry in Ciudad Juárez}

\author{
Marisela Nava* (D) https://orcid.org/0000-0002-0732-1099 \\ Aida Yarira Reyes Escalante ${ }^{\star *}$ (D) https://orcid.org/0000-0002-0104-9522 \\ Wendolyne Nava González ${ }^{* *}$ (iD https://orcid.org/0000-0003-0711-0598 \\ Sixta Cobos Floriano ${ }^{* * *}$ (iD https://orcid.org/0000-0002-0848-7410
}

\begin{abstract}
Resumen
El objetivo de la presente investigación es determinar la prevalencia del mobbing en las y los trabajadores de la industria maquiladora de exportación en Ciudad Juárez, Chihuahua, México, así como destacar las principales diferencias en tres niveles de puestos (gerencial, administrativo y operativo). Para la metodología se utilizaron técnicas cuantitativas y cualitativas a través de entrevistas semiestructuradas y se aplicó la escala de Cisneros por muestreo en dichas técnicas. Entre los resultados más relevantes se encontró una prevalencia del mobbing de $47 \%$ entre los trabajadores encuestados, así como la identificación de las principales víctimas y autores del acoso. Se pudo concluir que a pesar de la prevalencia del mobbing en la industria maquiladora de exportación, este fenómeno aún está normalizado por la mayoría de los trabajadores, por lo cual no existen mecanismos de apoyo eficaces para prevenir y sancionar estas conductas.

Palabras clave: mobbing; acoso laboral; violencia laboral; escala de Cisneros; industria maquiladora de exportación.
\end{abstract}

Cómo citar: Nava, M., Reyes Escalante,A.Y., Nava González,W., y Cobos Floriano, S. (2020). Prevalencia del mobbing en las y los trabajadores de la industria maquiladora en Ciudad Juárez. región y sociedad, 32, el 306. doi: 10.22 198/rys2020/32/I306

* Autora para correspondencia. Universidad Autónoma de Ciudad Juárez, Departamento de Ciencias Administrativas. Av. Heroico Colegio Militar s. n., Zona Chamizal, C. P. 32300, Ciudad Juárez, Chihuahua, México. Correo electrónico: marisela.nava@uacj.mx

** Universidad Autónoma de Ciudad Juárez, Departamento de Ciencias Administrativas. Av. Heroico Colegio Militar s. n., Zona Chamizal, C. P. 32300, Ciudad Juárez, Chihuahua, México. Correo electrónico: aida.reyes@uacj.mx

*** Universidad Autónoma de Ciudad Juárez, Departamento de Ciencias Jurídicas. Av. Heroico Colegio Militar s. n.,

Zona Chamizal, C. P. 32300, Ciudad Juárez, Chihuahua, México. Correo electrónico: wendolyne.nava@uacj.mx

**** Universidad Autónoma de Ciudad Juárez, Departamento de Ciencias Administrativas. Av. Heroico Colegio Militar s. n., Zona Chamizal, C. P. 32300, Ciudad Juárez, Chihuahua, México. Correo electrónico: sixta.cobos@uacj.mx

Recibido: 28 de febrero de 2020

Aceptado: 6 de julio de 2020

Liberado: 19 de agosto de 2020 


\section{Introducción}

El trabajo es una actividad necesaria e indispensable para el crecimiento, desarrollo y subsistencia del ser humano. Los nuevos retos y desafíos del mundo laboral exigen prestar atención a las situaciones de violencia física y psicológica que se suscitan dentro de las organizaciones de trabajo y que causan estragos en la salud, el bienestar y la dignidad de miles de trabajadores en todo el mundo. Gracias a las investigaciones sobre violencia laboral de las últimas décadas (Björkqvist, Österman y Hjelt-Back, 1994; Einarsen, Hoel, Zapf y Cooper, 2003; González y Rodríguez-Abuín, 2003; Hirigoyen, 1999; Leymann, 1996; Piñuel, 2001; Piñuel y Oñate, 2002; Zapf, Knorz y Kulla, 1996), enfocadas sobre todo en el mobbing, se ha dimensionado la gravedad del problema, lo cual ha obligado a organismos internacionales, como la Organización Internacional del Trabajo (OIT), la Unión Europea, la Organización Mundial de la Salud (OMS) y la Organización de las Naciones Unidas (ONU) en la Declaración Universal de Derechos Humanos, a proponer estrategias y recomendaciones para que los países de todo el mundo puedan prevenir, sancionar y aminorar lo más posible esta conducta (Piñuel y Oñate, 2004).

México no ha sido la excepción. Desde hace un par de décadas, decenas de investigadores mexicanos han logrado avances significativos, no sólo para acrecentar el acervo académico en este tema, sino también para visibilizarlo. Tal es el caso de los trabajos realizados por Manuel Pando Moreno, creador del Inventario de Violencia y Acoso Psicológico en el Trabajo (IVAPT-PANDO) (Pando, Aranda, Preciado, Franco y Salazar, 2006), y de las investigaciones de Florencia Peña Saint, Sergio Guadalupe Sánchez y Patricia Ravelo Blancas, quienes durante años han publicado y coordinado varios grupos de trabajo involucrados en el estudio e investigación de esta problemática, con el fin de promover su visibilidad, prevención, detección y regulación en el contexto mexicano. Pando (2011), en el Encuentro Internacional de la Salud Ocupacional, menciona que en México las investigaciones sobre mobbing han reportado que alrededor de $7 \%$ del total de la población económicamente activa (PEA) en el país sufre de violencia y acoso psicológico en su trabajo, es decir, más de 150000 trabajadores mexicanos. No obstante los avances que se han logrado a escala nacional, aún queda mucho por hacer.

El objetivo de esta investigación es determinar la prevalencia del mobbing en la industria maquiladora de exportación (IME) en Ciudad Juárez, Chihuahua, México, y destacar las principales diferencias entre los niveles gerencial, administrativo y operativo a partir de la metodología y del diagnóstico de la escala de Cisneros (Piñuel, 2001).

En la primera sección se abordan de manera general las principales aportaciones teóricas del mobbing. En la segunda se realiza una breve descripción del contexto donde se desarrolla la investigación. En la tercera se describe la metodología utilizada y los instrumentos de investigación. La cuarta sección está dedicada a la presentación de los resultados. Se divide en tres niveles: gerencial, administrativo y operativo. En la quinta sección se exponen las conclusiones y las recomendaciones. 


\section{Del mobbing}

Antecedentes del concepto

El mobbing no es un fenómeno nuevo. Podría decirse que es tan antiguo como las mismas organizaciones (Miguel y Prieto, 2016). Sin embargo, su estudio, conceptualización y sistematización tienen apenas unas cuantas décadas. El término aparece por primera vez en el campo de la etología a mediados de la década de 1960, cuando Konrad Lorenz observó cómo pequeñas especies de animales, considerados más débiles, se unían en grupo con el propósito de atacar a un animal solitario, de mayor tamaño, al cual consideraban una amenaza (Lorenz, 1971). Años más tarde, en 1969, Peter Paul Heinemann vuelve a hacer referencia a este concepto, adaptándolo al ámbito escolar, donde observó cómo un grupo de niños atacaban física y psicológicamente a un niño solitario. Heinemann manifestó su inconformidad con este tipo de conductas. Dijo que eran inaceptables y que la sociedad no debía tolerarlas (Larsson, 2016). Fue en la década de 1980 que Heinz Leymann detectó este mismo tipo de comportamientos en el ámbito laboral, donde un trabajador o un grupo de trabajadores intentaba destruir a otro, al cual consideraban una amenaza, mediante conductas persistentes de acoso (Leymann, 1992). Desde entonces la palabra mobbing ha sido utilizada para referirse a las situaciones de acoso psicológico dentro de las organizaciones de trabajo.

Concepto de mobbing

Desde el inicio de sus investigaciones, Leymann se esmeró en crear un concepto adecuado para describir esta conducta. Una de las definiciones más relevantes fue la de 1996, en la cual señala que es el

encadenamiento sobre un periodo de tiempo bastante corto de intentos o acciones hostiles consumadas, expresadas o manifestadas, por una o varias personas, hacia una tercera: el objetivo. El mobbing es un proceso de destrucción; se compone de una serie de actuaciones hostiles, que, tomadas de forma aislada, podrían parecer anodinas, pero cuya repetición constante tiene efectos perniciosos. (Leymann, 1996, p. 27)

Esta definición hace hincapié en las acciones hostiles que, hasta cierto punto, parecen inofensivas, pero las cuales pueden llegar a convertirse en un proceso de destrucción para el individuo que las sufre de manera constante. A raíz de este concepto han surgido numerosos estudios. Tal es el caso de la definición que en 2001 propone Marie France Hirigoyen en su estudio El acoso moral en el trabajo: "Todo comportamiento abusivo (gesto, palabras, comportamientos, actitudes...) que atenta por su repetición y sistematicidad a la dignidad o a la integridad psíquica o física de una persona, poniendo en peligro su empleo o degradando el clima de trabajo" (Hirigoyen, 2001, p. 13). Hirigoyen continúa con la idea de Leymann de la periodicidad del comportamiento; sin embargo, es un poco más específica en cuanto a las formas en que éste puede presen- 
tarse, que van desde simples palabras y gestos, hasta actitudes hirientes que causan un daño a la dignidad e integridad física del trabajador. Entre las definiciones más completas de este fenómeno, se encuentra la de Iñaki Piñuel, quien lo define como:

el continuado y deliberado maltrato verbal y modal que recibe un trabajador por parte de otro u otros, que se comportan con él cruelmente con el objeto de lograr su aniquilación o destrucción psicológica y a obtener su salida de la organización a través de diferentes procedimientos ilegales, ilícitos, o ajenos a un trato respetuoso o humanitario y que atentan contra la dignidad del trabajador. El mobbing tiene como objetivo intimidar, apocar, reducir, aplanar, amedrentar y consumir, emocional e intelectualmente a la víctima, con vistas a eliminarla de la organización o a satisfacer la necesidad insaciable de agredir, controlar y destruir que suele presentar el hostigador, que aprovecha la ocasión que le brinda la situación organizativa particular (reorganización, reducción de costes, burocratización, cambios vertiginosos, etc.) para canalizar una serie de impulsos y tendencias psicopáticas. (Piñuel, 2001, p. 55)

Esta definición ofrece una explicación detallada de los modos de operar, así como los principales objetivos del mobbing, poniendo el énfasis en la destrucción o salida del trabajador de la organización. Estas definiciones tienen un elemento en común. Todas señalan que los comportamientos deben ser repetidos y persistentes, características que resultan esenciales para diferenciar el mobbing de cualquier conflicto laboral ocasional. Einarsen, Hoel, Zapf y Cooper (2003), Leymann (1992) y Piñuel (2015) mencionan que para que exista se debe cumplir con al menos tres premisas: 1) una o más conductas de hostigamiento aceptadas y reconocidas por expertos en el tema; 2) la duración del hostigamiento no debe ser esporádica sino prolongada durante un periodo de seis meses como mínimo; y 3) las conductas de hostigamiento deben ser repetidas al menos una vez por semana (Piñuel y Oñate, 2004). Si estas tres premisas se cumplen, se puede afirmar que un trabajador es víctima de mobbing.

Con base en las definiciones sugeridas y reuniendo los elementos clave de cada una de ellas, se puede decir que el mobbing se refiere a las acciones y comportamientos hostiles, violentos y abusivos, en todas sus diferentes formas, de una o varias personas hacia otra (la víctima), ya sea de forma ascendente, descendente u horizontal en un entorno laboral. Se presentan de manera repetida (por lo menos una vez por semana) y persistente (por un período mínimo de seis meses), y tienen como objetivo infringir un daño físico, psicológico o profesional a la víctima. Todos los esfuerzos para conceptualizar este fenómeno han sido, en palabras de Leymann, quizás el aporte más significativo de la comunidad científica que se ocupa del mobbing (Piñuel, 2015), ya que en el pasado una gran cantidad de trabajadores sufrían enormes daños psicológicos y físicos a causa del acoso y sin embargo eran incapaces de explicar con exactitud qué era lo que sucedía. Gracias a la aparición de este término, hoy los trabajadores pueden saber que están siendo víctimas de mobbing. 
Causas y sujetos del mobbing

A pesar de que el mobbing ha sido objeto de numerosos estudios, aún resulta difícil determinar cuáles son las causas específicas que lo generan. A pesar de que no existe consenso sobre las causas concretas, hay algunas coincidencias que podrían ayudar a saber quiénes son los sujetos propensos a sufrir esta conducta y cuáles son las principales motivaciones. Por ejemplo, por lo regular el perfil de la víctima es una persona bien calificada que se destaca en el ámbito profesional y cuyas cualidades resultan amenazantes para el hostigador (González y Rodríguez, 2003; Piñuel y Oñate, 2004). En el caso del hostigador, por lo general es una persona mediocre que posee rasgos narcisistas e incluso psicopáticos, con una alta necesidad de control (Vidal, 2006).

Formas e instrumentos para el diagnóstico del mobbing

En las últimas décadas, algunos especialistas del tema han desarrollado una serie de instrumentos para detectar la prevalencia del mobbing dentro de las organizaciones, cada uno de ellos con sus propias dimensiones e indicadores. El primer instrumento fue el cuestionario Leymann Inventory of Psychological Terrorization (LIPT), desarrollado por Leymann (1996), en donde clasifica 45 conductas distribuidas en 5 dimensiones (véase tabla 1).

De estas dimensiones e indicadores surgen otras propuestas y modelos similares. Por ejemplo, Zapf, Knorz y Kulla (1996), proponen clasificar las conductas de hostigamiento (contenidas en su mayoría en el LIPT) en tipos de ataque, a saber 1) con fines organizacionales, 2) con fines de aislamiento social, 3) a la vida privada de la víctima, 4) sexuales, 5) a la nacionalidad, religión y creencias políticas de la víctima, así como una categoría exclusiva, 6) rumores.

Más adelante, en 2001 aparece en España el barómetro de Cisneros mediante el cual Piñuel propone una serie de estrategias utilizadas por los acosadores para someter a sus víctimas. Consiste en 43 conductas de acoso psicológico muy relacionadas con los indicadores del LIPT (véase tabla 1). Piñuel va más allá de la determinación de la presencia del mobbing cuando evalúa las consecuencias, sobre todo en la salud, y los factores de riesgo. También caracteriza los perfiles del acosador, de la víctima y las formas de organización del trabajo en las empresas.

En el caso de México, en 2006, surge el inventario de violencia y acoso psicológico en el trabajo (IVAPT-PANDO), de Pando, el primer instrumento desarrollado y validado en México y en América Latina para determinar la presencia y la intensidad de la violencia, así como el acoso psicológico laboral. Pando et al. (2006) describen conductas muy similares a las propuestas por Leymann, sintetizándolas en 22 preguntas, además de medir la frecuencia e identificar quiénes son los autores del acoso. El IVAPT-PANDO también mide la intencionalidad. Pando et al. (2006) explican que para que dichas conductas sean consideradas acoso, éstas deben ser llevadas a cabo con la intención de aniquilación o destrucción psicológica del trabajador. 
Tabla 1. Dimensiones e indicadores del mobbing de Leymann

\begin{tabular}{|c|c|}
\hline Dimensión & Indicadores \\
\hline $\begin{array}{l}\text { Autoestima y } \\
\text { canales de } \\
\text { comunicación }\end{array}$ & $\begin{array}{l}\text { Restricciones para expresarse. } \\
\text { Gritos y regaños en voz alta. } \\
\text { Críticas constantes. } \\
\text { Acoso por teléfono. } \\
\text { Amenazas verbales o escritas. }\end{array}$ \\
\hline $\begin{array}{c}\text { Relaciones sociales } \\
\text { personales }\end{array}$ & $\begin{array}{l}\text { Se le niega al trabajador el acceso a otros. } \\
\text { Un lugar de trabajo aislado de los demás. } \\
\text { Se prohíbe a los compañeros que hablen con la víctima. } \\
\text { Ser tratado como invisible. }\end{array}$ \\
\hline $\begin{array}{l}\text { Reputación } \\
\text { del trabajador }\end{array}$ & $\begin{array}{c}\text { Circulación de rumores infundados. } \\
\text { Se ridiculiza una discapacidad, creencias políticas o religiosas, } \\
\text { vida privada, nacionalidad. } \\
\text { Juzgar esfuerzos de modo erróneo y degradante. } \\
\text { Cuestionar siempre sus decisiones. } \\
\text { Ser llamado con nombres denigrantes. } \\
\text { Insinuaciones sexuales. }\end{array}$ \\
\hline $\begin{array}{c}\text { Calidad profesional } \\
\text { y situación vital }\end{array}$ & $\begin{array}{l}\text { No existen tareas específicas. } \\
\text { Los supervisores asignan tareas sin valor o sin significado. } \\
\text { Se asignan tareas por debajo de la cualificación. } \\
\text { Tareas que afectan la autoestima. } \\
\text { Daños generales que crean costos económicos para el empleado. } \\
\text { Daños a su casa o lugar de trabajo. }\end{array}$ \\
\hline Salud & $\begin{array}{l}\text { Trabajo físico fuerte. } \\
\text { Amenazas de violencia física. Violencia ligera para amenazar. } \\
\text { Abuso físico. } \\
\text { Acoso sexual directo. }\end{array}$ \\
\hline
\end{tabular}

Fuente: elaboración propia basada en Leymann (1992).

\section{Consecuencias del mobbing}

El mobbing ha sido catalogado como una epidemia que no sólo trae consecuencias para las organizaciones, sino también fuera de ellas. Algunos expertos en el campo de la psicología laboral han estudiado por años sus efectos dañinos en el ámbito personal, familiar, organizacional y social (Zapf y Einarsen, 2001). Un trabajador que está expuesto a situaciones de mobbing puede llegar a presentar distintos síntomas, derivados sobre todo del estrés y la ansiedad, lo que puede provocar cambios en su personalidad e incluso daños severos en su salud. Piñuel (2001) engloba los trastornos más relevantes de los cambios en la personalidad en tres categorías: 1) la personalidad obsesiva, la cual viene acompañada de conductas hostiles y nerviosismo crónico; 2) la personalidad depresiva, caracterizada sobre todo por sentimientos de vacío y desesperanza que pueden llegar a generar conductas adictivas y, por último, 3) la personalidad resignada, en la que la víctima no se siente parte de la sociedad. En cuestiones de salud, 
es innumerable la cantidad de síntomas que pueden presentarse. Piñuel (2001) hace referencia a síntomas y efectos, tales como el desgaste físico producido por el continuo estrés, trastornos del sueño, cansancio, debilidad y síntomas psicosomáticos de estrés, como pesadillas, dolores de estómago, náuseas y vómitos. También hay efectos cognitivos e hiperreacción psíquica, como la pérdida de memoria, depresión, irritabilidad, agresividad, apatía y sentimientos de inseguridad.

La presencia de uno o varios de estos síntomas pone en riesgo no sólo la salud física y mental del trabajador, sino que también perjudica las relaciones de éste con su entorno (Martín, Pérez y López, 2002; Piñuel, 2015). Por ejemplo, a nivel organizacional, el cansancio, la desmotivación y la falta de concentración pueden repercutir en el rendimiento profesional del trabajador y generar altos índices de absentismo, incapacidades por enfermedad, accidentes de trabajo y a largo plazo provocar su salida de la organización (Agervold, 2009). De igual forma, las consecuencias de dicha sintomatología pueden afectar la vida personal del trabajador: incremento de los conflictos familiares y, en casos extremos, un ambiente de violencia doméstica. Una víctima de mobbing también produce efectos negativos en la sociedad, debido a los diferentes costos económicos derivados de la atención médica, el desempleo, las pensiones por invalidez y los problemas sociales que genera (Martín et al., 2002).

\section{Del mobbing en la IME en Ciudad Juárez}

La IME en Ciudad Juárez

La industria maquiladora de exportación (IME) comenzó como un plan emergente a mediados de la década de 1960 para contrarrestar el problema del desempleo masivo de miles de mexicanos instalados en la frontera norte del país por el término del Programa Braceros con Estados Unidos (Contreras y Munguía, 2007). A pesar de que dicha iniciativa prometió ser una solución temporal (Contreras y Munguía, 2007), su impacto ha sido tal que en 2004 la IME era uno de los sectores más importantes para la economía mexicana (Carrillo, 2004). Cientos de miles de trabajadores mexicanos laboran en esa industria, y Ciudad Juárez es una de las ciudades más representativas de ese sector en todo el país. Ésta cuenta con una PEA de 530456 habitantes, de los cuales 280589 trabajan en la industria maquiladora. Esto representa 53\% de la PEA (Instituto Nacional de Estadística y Geografía [INEGI], 2019). En la actualidad, existen alrededor de 330 maquiladoras, distribuidas en 23 parques y 15 zonas industriales en la ciudad (INEGI, 2019). Desde su llegada a México, la IME ha evolucionado de manera significativa. Es innegable su crecimiento y progreso en cuanto a infraestructura, procesos, introducción de nuevas tecnologías e incluso de mano de obra calificada (Carrillo, 2004). Sin embargo, este desarrollo, impulsado por la competencia y las altas demandas de un mercado cada vez más globalizado, ha hecho que las intensas cargas y ritmos acelerados de trabajo sean características inherentes de esa industria. Dichas exigencias a veces pueden generar ambientes tóxicos de trabajo e incluso convertirse en un escenario perfecto 
para la aparición de situaciones de mobbing (Björkqvist et al., 1994; Leymann, 1996).

\section{Metodología}

Diseño de la investigación

Por su ubicación temporal, esta investigación es prospectiva de corte trasversal, ya que los datos fueron obtenidos y registrados una sola vez. Para determinar la prevalencia del mobbing en la IME, se utilizaron técnicas cualitativas y cuantitativas a través de entrevistas semiestructuradas y se aplicó en ambas la escala de Cisneros.

Población y cálculo de la muestra

Se consideró como universo de estudio a todos los trabajadores de la IME en Ciudad Juárez. Para conocer el número de trabajadores que componen el universo, se utilizaron los datos de la Estadística Integral del Programa de la Industria Manufacturera, Maquiladora y de Servicios de Exportación (IMMEX) realizada al mes por el INEGI (2019). El tamaño de la población en mayo de 2019 fue de 280589 trabajadores.

Para el cálculo de la muestra se empleó el programa Decision Analyst STATS ${ }^{\text {TM }}$ 2.0. De un universo de 280589 trabajadores, cuyo nivel de confianza es de $95 \%$, que tiene un margen de error de $5 \%$ y un porcentaje de heterogeneidad de $50 \%$, se obtuvo una muestra de 384 trabajadores.

Instrumentos de investigación

Escala de Cisneros

Para los fines de esta investigación y debido a su alta fiabilidad y validez (Fidalgo y Piñuel, 2004), se consideró pertinente utilizar la escala de Cisneros, diseñada para evaluar el grado de acoso psicológico en el trabajo y cuyo diseño objetivo y sistemático permite aplicarse a cualquier trabajador proveniente de cualquier tipo de organización. La escala de Cisneros, como lo explican Fidalgo y Piñuel (2004), pertenece a una de las tres escalas del barómetro de Cisneros. Es un cuestionario autodirigido, integrado por 43 conductas de acoso psicológico, en donde el trabajador señala, además de la conducta, la frecuencia (nunca, pocas veces al año, algunas veces al año, mensual, semanal o diario), así como al autor o autores del acoso (jefe, compañero o subordinado). Tomando como base la posición jerárquica de los victimarios con respecto a la víctima, la escala utiliza los siguientes términos:

- Compañero de trabajo que se encuentra en el mismo nivel jerárquico que el encuestado.

- Jefe: aquella persona que se encuentra en un nivel jerárquico superior y el cual posee cierta autoridad para dirigir las tareas del trabajador encuestado. 
- Subordinado: trabajador con un nivel jerárquico menor que se encuentra bajo el mando del trabajador encuestado.

Debido a que el cuestionario fue elaborado para medir el acoso psicológico en España, la encuesta contenía ciertos modismos propios del país, por lo cual hubo que sustituirlos por los que se usan en México. Así mismo, previo a la aplicación de la escala, se agregó el apartado datos sociodemográficos y laborales del trabajador, en el que se incluyó el sexo, el rango de edad, el estado civil, el nivel de estudios, el puesto y la antigüedad, entre otros datos.

Para facilitar el manejo de la información, la presente investigación dividió los puestos de trabajo en tres niveles: gerencial, administrativo y operativo. Dicha clasificación se hizo con base en los datos del programa IMMEX, que divide a los trabajadores en dos niveles: el nivel operativo, que incluye a todos los obreros (operadores) y técnicos de producción, y el nivel administrativo, que incluye a los empleados administrativos, contables y de dirección. Para los fines de este estudio, se decidió separar a los directivos en un tercer nivel, el gerencial, ya que en algunos estudios se afirma que las personas que ocupan los puestos gerenciales son quienes padecen más de mobbing.

Se aplicaron 384 cuestionarios, tanto de manera física como virtual a través de un formulario electrónico, según fuera el caso. Para la captura de la información, se utilizaron aplicaciones tecnológicas con el fin de reducir el tiempo de captura y dedicar más tiempo al análisis de la información.

\section{Entrevistas semiestructuradas}

Se realizaron 17 entrevistas a los trabajadores de la IME, distribuidas de la siguiente manera: 9 a los obreros y a los técnicos de producción, 5 a los empleados administrativos y 3 a los gerentes. Respecto al grado de estructuración, se optó por una entrevista personal semiestructurada utilizando un muestreo por conveniencia; es decir, sólo se realizaron entrevistas a quienes desearon colaborar. La información recabada fue confidencial, por lo cual los entrevistados usaron un seudónimo que hace referencia sólo a la edad, el sexo y el puesto.

Después de un análisis detallado del marco teórico y tomando como base el objetivo de la investigación, se diseñó un guion sencillo para la aplicación de las entrevistas. Para su desarrollo, se elaboraron preguntas guías, entre las que se incluyeron algunas sobre el grado de conocimiento del tema; y otras más específicas sobre sus experiencias personales, acontecimientos y percepciones sobre el mobbing. Una vez recabada la información, se procedió a analizarla para sistematizar y describir los resultados.

\section{Resultados y discusión}

Datos generales

La muestra está compuesta por 204 hombres, quienes representan 53\% del total de la población, y 180 mujeres, que representan el restante $47 \%$. Respecto a la 
edad de los encuestados, 154 trabajadores se encuentran en un rango de entre 18 y 25 años (40\%), seguido de los 104 trabajadores mayores de 40 años (27\%). En términos generales, la IME está compuesta en su mayoría por operadores de producción $(90 \%)$. La demanda de obreros de producción de las empresas maquiladoras en Ciudad Juárez es muy alta, por lo que los requisitos para ocupar dichos puestos son mínimos: no se requieren altos niveles de estudio ni experiencia ni capacitación. Por eso los más jóvenes y las personas mayores de 40 años (quienes tienen más dificultad en posicionarse en otros mercados laborales) acuden a solicitar este tipo de empleos. Los rangos de los trabajadores de 26 a 30 años (15\%) y de 31 a 40 (18\%) corresponden en su mayoría a los niveles administrativo y gerencial.

En cuanto a los puestos, hay una infinidad en la IME. Si se incluyeran todos, resultaría difícil e incluso imposible analizarlos, porque muchos de ellos no son comparables entre sí. Por esa razón se agruparon en tres niveles: gerencial, administrativo y operativo. En este caso, la muestra se compone de $70 \%$ de trabajadores pertenecientes al nivel operativo, en el que se incluyen los operadores y los técnicos de producción, $22 \%$ de empleados en el nivel administrativo y $8 \%$ de directivos en el nivel gerencial (véase tabla 2).

Tabla 2. Nivel de puestos de los trabajadores

\begin{tabular}{|c|c|c|}
\hline Nivel & Frecuencia & Porcentaje \\
\hline Gerencial & 29 & 8 \\
\hline Administrativo & 85 & 22 \\
\hline Operativo & 270 & 70 \\
\hline Total & 384 & 100 \\
\hline
\end{tabular}

Fuente: elaboración propia con base en las encuestas.

Con el fin de determinar la prevalencia de mobbing, se contemplaron los parámetros sugeridos en el marco teórico; es decir, que los trabajadores manifestaran haber sufrido al menos una de las 43 conductas contenidas en la escala de Cisneros por un periodo mínimo de seis meses y con una frecuencia de por lo menos una vez por semana. Los resultados fueron los siguientes: 181 trabajadores manifestaron sufrir algún tipo de mobbing (47\%). El otro 53\%, a quienes se les consideró no víctimas de mobbing, señalaron haber sufrido por lo menos una de las conductas señaladas en la escala; sin embargo, no cumplían con los requisitos de frecuencia y periodicidad (véase tabla 3 ).

Tabla 3. Trabajadores víctimas y no víctimas de mobbing

\begin{tabular}{|c|c|c|}
\hline Mobbing & Frecuencia & Porcentaje \\
\hline No víctimas & 203 & 53 \\
\hline Víctimas & 181 & 47 \\
\hline Total & 384 & 100 \\
\hline
\end{tabular}

Fuente: elaboración propia con base en las encuestas. 
Total de víctimas de mobbing

A continuación se presenta la descripción de las características de las víctimas de mobbing. De los 181 trabajadores que manifestaron ser víctimas de mobbing, 81 son hombres y 100 son mujeres. Si se realiza una comparación con el total de la muestra, 100 de las 180 mujeres encuestadas manifestó haber sufrido por lo menos alguna conducta de mobbing, lo que equivale a $56 \%$. En el caso de los hombres, de los 204 encuestados, 40\% de ellos, es decir 81 hombres, manifestaron ser víctimas. Ambos porcentajes resultan alarmantes, pues son elevados. Los estudios internacionales para determinar la prevalencia de la violencia y el acoso psicológico en el trabajo o mobbing alcanzan valores que van desde $3.5 \%$ hasta $79 \%$, (la variación en los porcentajes depende del sector laboral y del instrumento de medición utilizado) (Pando, Aranda y Olivares, 2012). Sin embargo, Pando et al. (2006) indican que las cifras superiores a 25\% deberían reconsiderarse. Proponen para ello una revisión detallada de constructos y el uso de criterios más restrictivos para validar los instrumentos utilizados en las investigaciones. Están convencidos de que el propósito de las organizaciones no está encaminado a la destrucción de los individuos (Pando et al., 2006). Es recomendable validar dicho instrumento cuando se aplique al contexto mexicano.

En cuanto a la edad de las víctimas, de los 154 encuestados que se encuentran en un rango de edad de entre 18 y 25 años, 94 trabajadores son víctimas (61\%). Muy de cerca están los que tienen entre 26 y 30 años (51\%). En los datos recabados, se puede observar que conforme avanza el rango de edades, en comparación con los totales, los porcentajes disminuyen de manera significativa. Tal es el caso de los trabajadores en el rango de 31 a 40 (36\%) y los que tienen más de 40 años (32\%) (véase tabla 4).

Tabla 4. Mobbing por rangos de edad

\begin{tabular}{|l|c|c|c|}
\hline $\begin{array}{l}\text { Rango } \\
\text { de edad }\end{array}$ & $\begin{array}{c}\text { Víctimas de } \\
\text { mobbing }\end{array}$ & $\begin{array}{c}\text { Total de la } \\
\text { muestra }\end{array}$ & $\begin{array}{c}\text { Porcentaje de víctimas } \\
\text { del total de la muestra }\end{array}$ \\
\hline De 18 a 25 años & 94 & 154 & 61 \\
\hline De 26 a 30 años & 29 & 57 & 51 \\
\hline De 31 a 40 años & 25 & 69 & 36 \\
\hline Más de 40 años & 33 & 104 & 32 \\
\hline Total & 181 & 384 & \\
\hline
\end{tabular}

Fuente: elaboración propia con base en las encuestas.

En la mayoría de los casos, la edad está ligada con la antigüedad. Un dato que resulta interesante fue la normalización del acoso. Buena parte de los trabajadores entrevistados consideraron el acoso como algo habitual en la dinámica de trabajo en la IME. Éstos son algunos de sus comentarios: 
Tengo más de diez años trabajando en la maquila y el ambiente de trabajo es así, o te acostumbras o te sales. (Operador de 43 años)

He trabajado en varias maquilas y siempre es lo mismo. Hay muchas envidias y gente que no le gusta verte progresar, pero así es en todos lados, ¿no? (Compradora (buyer) de 38 años)

Los nuevos que entran se quejan mucho. Todos los trabajos son difíciles y no te vas a salir por los pleitos con tus compañeros. (Operador de 54 años)

¿En qué consiste la normalización del acoso? A pesar de los valiosos aportes de investigadores mexicanos (Fuentes, 2008; Pando et al., 2006; Peña y Sánchez, 2007; Sánchez y Ambrosio, 2010; Sánchez, Ravelo y Melgoza, 2015), quienes han logrado visibilizar la existencia de este fenómeno en el país, en materia organizacional y legal aún hay un largo camino que recorrer. En el caso de las empresas mexicanas, un gran número de trabajadores y empleadores todavía desconoce el tema, por lo que a menudo el mobbing llega a confundirse con conflictos entre personas o es considerado como parte de la carga habitual de trabajo. Debido a que no existe una legislación específica, es comprensible que las empresas desconozcan o incluso pasen por alto este tipo de situaciones. Esto no significa que no haya avances significativos respecto a su regulación ni mucho menos que los trabajadores se encuentren totalmente desprotegidos. Por ejemplo, la Ley Federal del Trabajo de México tiene disposiciones para sancionar algunas de las conductas pertenecientes al mobbing, tales como la discriminación, la violencia, el hostigamiento y el acoso sexual, contenidas en los artículos 3, 3 bis, 47, frac. VIII y 51, frac. II de la ley. En lo referente a los riesgos psicosociales, un avance importante fue la Norma Oficial Mexicana 035 (NOM-035-STPS-2018), emitida por la Secretaría del Trabajo y Previsión Social (STPS), que entró en vigor en octubre de 2019 y que tiene como objetivo: "establecer los elementos para identificar, analizar y prevenir los factores de riesgo psicosociales así como para promover un entorno organizacional favorable en los centros de trabajo" (STPS, 2018). Esta norma se debería aplicar en todos los centros de trabajo del país de manera obligatoria. Sin embargo, para muchas empresas todavía resulta algo confusa y para otras es desconocida.

Pese a todos los avances ya descritos, la figura específica del mobbing aún no se encuentra tipificada en la ley. En 2014 la Primera Sala de la Suprema Corte de Justicia de la Nación emitió una resolución -Tesis CCLI/2014 (10a) - en la que reconoció la existencia del mobbing. En ella hay una descripción precisa que incluye su definición, tipos, formas y conductas y que pone el énfasis en la violación de los derechos humanos del trabajador. No obstante, la resolución no logró convertirse en jurisprudencia, por lo que su alcance sólo se limita a brindar orientación a las autoridades competentes para la interpretación de conflictos sobre el tema. Como menciona Morales (2016), el tratamiento jurídico aún no está resuelto, por lo que se requiere una ley específica integral que abarque todos sus aspectos no sólo para sancionar, sino también para prevenir y erradicar la conducta. 
Se analizó el mobbing en cada uno de los niveles de puestos (gerencial, administrativo y operativo), con el fin de saber si hay diferencias significativas entre ellos y, a su vez, para determinar en cuál nivel las situaciones de mobbing son más frecuentes. Los datos muestran que de los 29 gerentes encuestados, 11 son víctimas (38\%), en el nivel administrativo, 34 (40\%) y en el nivel operativo, $136(50 \%)$.

Mobbing por nivel de puesto

Nivel gerencial

En el estudio se encontró que de la muestra compuesta por 384 trabajadores, 29 pertenecen a puestos directivos: $83 \%$ hombres y $17 \%$ mujeres; $61 \%$ hombres y mujeres de 40 años o más; $17 \%$ tiene de 31 a 40 años y $22 \%$ de 26 a 30 años. Respecto a su estado civil, $67 \%$ son casados, $17 \%$ son divorciados y $17 \%$ son solteros. Toda la población cuenta con estudios universitarios: $83 \%$ tiene sólo licenciatura y $17 \%$ cuenta con por lo menos un posgrado. En cuanto a la antigüedad, $21 \%$ cuenta con más de 10 años, 12\% tiene entre 5 y 10 años, 44\% entre 1 y 5 años y $23 \%$ menos de un año. En relación con los turnos de trabajo, cabe destacar que 99\% trabaja en turno matutino y $1 \%$ no tiene definición de turno.

Como se mencionó en el apartado anterior, 38\% de los encuestados en esta categoría ha sido víctima de algún tipo de mobbing. De los hombres, $27 \%$ manifestó padecerlo, mientras que $100 \%$ de las mujeres encuestadas padece algún tipo de acoso. Numerosos estudios organizacionales han demostrado que un alto porcentaje de mujeres en México se enfrenta a los conocidos techos de cristal, barrera invisible que impide a las mujeres muy capacitadas tener acceso a puestos de dirección en una empresa. A base de mucho esfuerzo, la mujer hoy en día ha logrado alcanzar puestos directivos; sin embargo, al llegar ahí son muchas las dificultades a las que se enfrenta. Algunas gerentes externaron lo siguiente:

Si te fijas, somos muy pocas las que tenemos estos puestos. Primero tenemos que trabajar el doble que los hombres para conseguirlos, y una vez que estamos aquí, tenemos que trabajar mucho más para demostrar que sí podemos con el puesto [...]. A los hombres no les gusta que tengamos puestos de poder y siempre están poniéndonos el pie para sacarnos de la jugada. (Mujer gerente de 49 años)

Trabajar en un mundo de hombres es desgastante. Las miradas siempre están sobre ti [...]. Todo el tiempo te están observando y criticando. ¡Ah! ¡Y cualquier error que cometas, lo hacen muy grande! No pasa lo mismo entre ellos. (Mujer gerente del departamento de compras de 55 años)

Si eres mujer, en las reuniones de directivos [donde la mayoría son hombres] te ignoran y te excluyen. (Mujer gerente del departamento de recursos humanos) 
Los resultados reflejan que los principales autores de mobbing en el nivel gerencial son los jefes (55), los compañeros (36) y los subordinados (9) (véase figura 1).

Figura 1. Autores de mobbing en el nivel gerencial

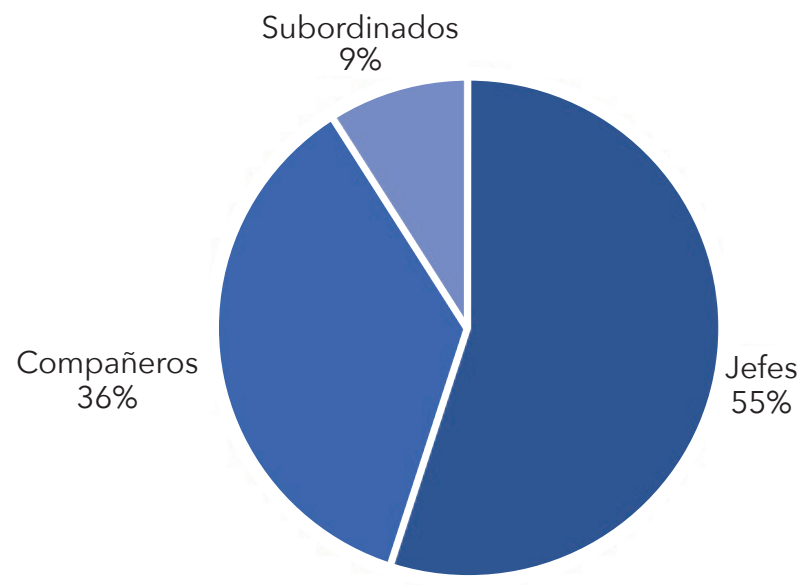

Fuente: elaboración propia con base en las encuestas.

Los jefes presionan de manera constante a sus trabajadores para cumplir con la producción y los tiempos de entrega. Sin embargo, a veces esa presión llega a convertirse en mobbing. Uno de los gerentes relató esto:

La presión que tenemos nosotros, los gerentes, es demasiada. Los dueños siempre quieren las cosas para ayer. Yo entiendo que debemos sacar el trabajo adelante, pero no a gritos ni con malos tratos; he tenido jefes que me han empujado o lanzado cosas cuando algo sale mal. (Hombre gerente de 37 años)

En el caso de los compañeros, el mobbing es causado por las envidias y la competencia entre ellos por los puestos de trabajo.

Estos puestos son muy deseados. Tienes que cuidarlo mucho. La gente es muy envidiosa y siempre te está criticando o inventando chismes. (Hombre gerente de producción de 47 años)

Los mandos gerenciales manifestaron sufrir acoso en 22 de las 43 conductas contenidas en la escala de Cisneros. Las conductas más recurrentes fueron no poderse expresar (64\%) y ser ignorados, poco valorados y recibir una presión indebida para hacer el trabajo (55\%). Los plazos, las cargas de trabajo absur- 
das y la evaluación injusta de su trabajo ocupan el tercer lugar con 45\% (véase figura 2).

Figura 2. Conductas más frecuentes de mobbing en el nivel gerencial

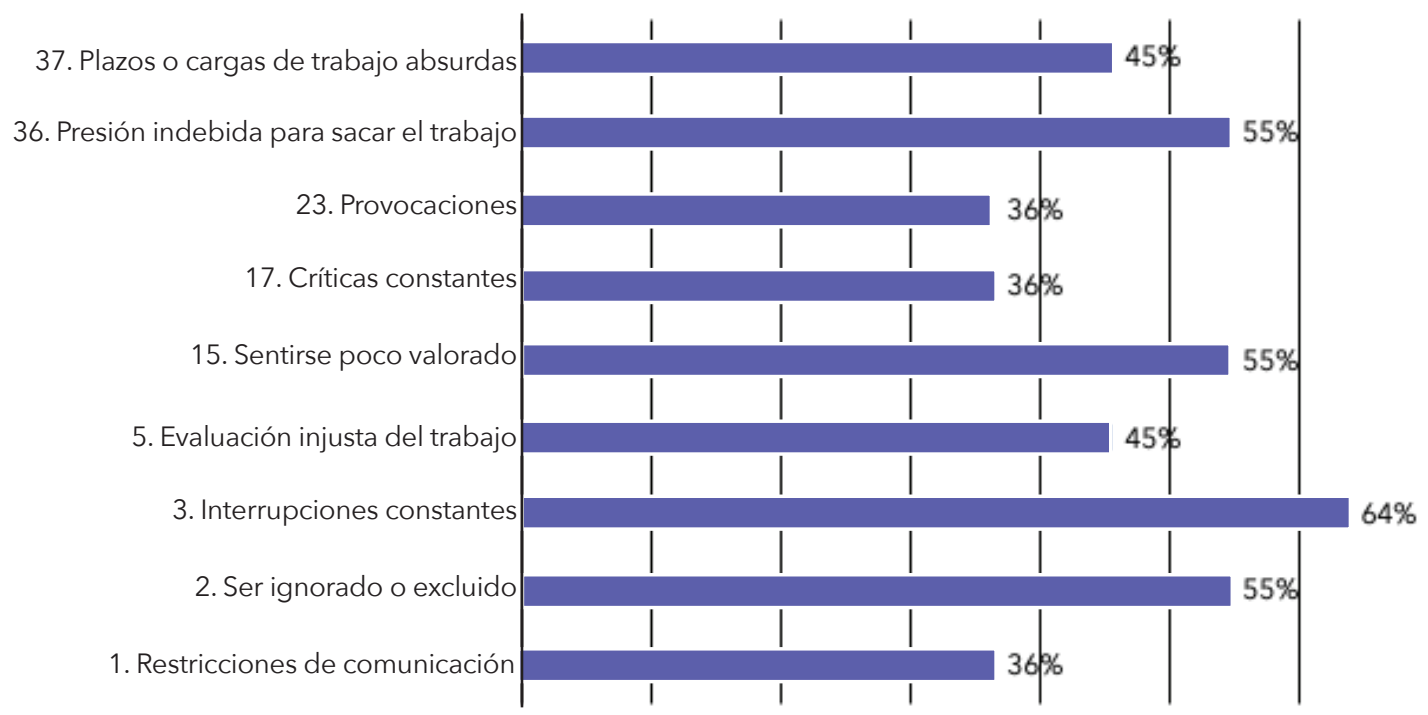

Fuente: elaboración propia con base en las encuestas.

\section{Nivel administrativo}

De los encuestados, 85 trabajadores son empleados administrativos. Son hombres $67 \%$ y $33 \%$ mujeres. Los rangos de edad corresponden en $61 \%$ a los trabajadores de más de 40 años; en 22\% a los de 31 a 40 años y en 17\% a los de 26 a 30 años. De los administrativos, hay $40 \%$ de casados, $8 \%$ de divorciados, $38 \%$ de solteros y $14 \%$ vive en unión libre. La población que cuenta sólo con estudios de primaria es de $2 \%$, sólo con secundaria $8 \%$ y sólo con preparatoria $42 \%$; $48 \%$ tiene estudios universitarios. Respecto a la antigüedad, 39\% tiene entre 1 y 5 años; $28 \%$ entre 5 y 10 años; $27 \%$ tiene más de 10 años en la misma empresa y 6\% tiene menos de un año. Se encontró que $40 \%$ de los encuestados en esta categoría ha sido víctima de mobbing: $60 \%$ de mujeres y $40 \%$ de hombres.

Respecto a los autores del mobbing en este nivel, 63\% corresponde a los jefes, $20 \%$ a los compañeros, $10 \%$ a los subordinados y el restante $7 \%$ a todos (véase figura 3). 
Figura 3. Autores del mobbing en el nivel administrativo

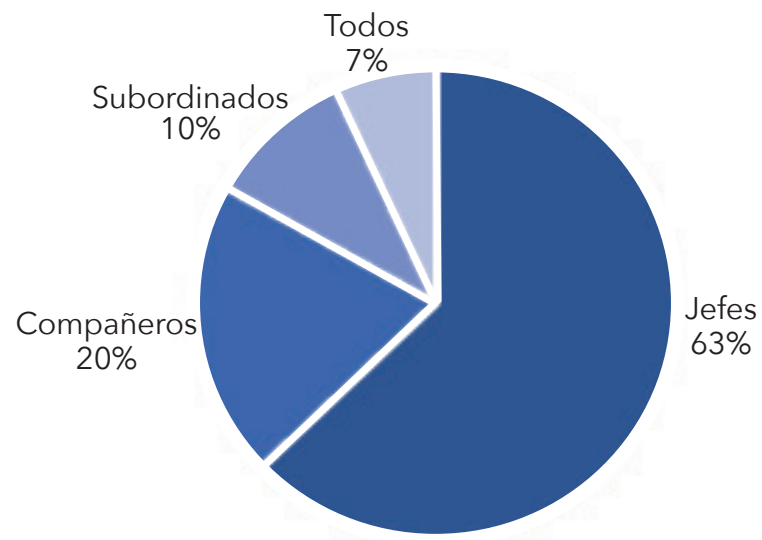

Fuente: elaboración propia con base en las encuestas.

De los comportamientos más frecuentes en este nivel se encuentran: sentirse poco valorados (62), el trabajo evaluado de manera injusta (44), la asignación de tareas rutinarias sin ningún valor y no poder comunicarse ni hablar (35), seguido de sentirse ignorado y/o excluido, así como las cargas y plazos de trabajo absurdas (32) (véase figura 4).

Figura 4. Comportamientos más frecuentes de mobbing

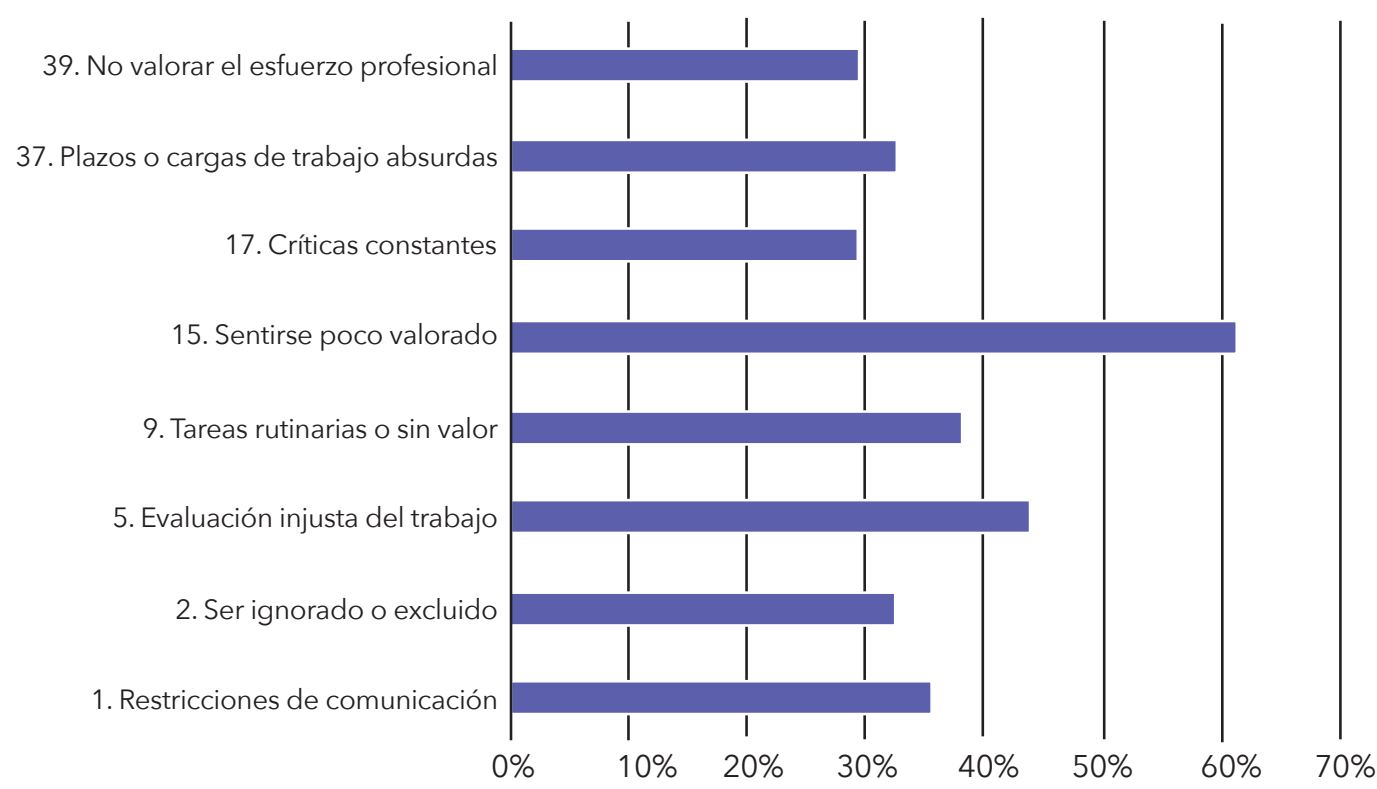

Fuente: elaboración propia con base en las encuestas. 


\section{Nivel operativo}

Este nivel consta de 270 operadores y técnicos de producción, $45 \%$ de hombres y $55 \%$ de mujeres. Los rangos de edad corresponden en $46 \%$ de 18 a 25 años, $21 \%$ de 40 o más, $17 \%$ de 26 a 30 años y $16 \%$ de 31 a 40 años. De esta población, $54 \%$ son solteros, $26 \%$ casados, $12 \%$ vive en unión libre, $6 \%$ divorciados y $2 \%$ viudos. La población cuenta con estudios de primaria (4\%), secundaria (31\%), preparatoria (38\%) y universidad (27\%). Respecto a los años de antigüedad, el mayor porcentaje (42\%) tiene menos de un año de antigüedad; $38 \%$ entre 1 y 5 años, $10 \%$ más de 10 años y 10\% tiene una antigüedad de entre 5 y 10 años. Se encontró que $58 \%$ de los encuestados en este nivel ha sufrido mobbing; $40 \%$ son hombres y $60 \%$ son mujeres. De nuevo las mujeres son quienes más sufren de mobbing.

En la figura 5 se muestra que los principales autores de mobbing son los jefes (61), compañeros de trabajo (27) y ambos (12).

Figura 5. Autores de mobbing en el nivel operativo

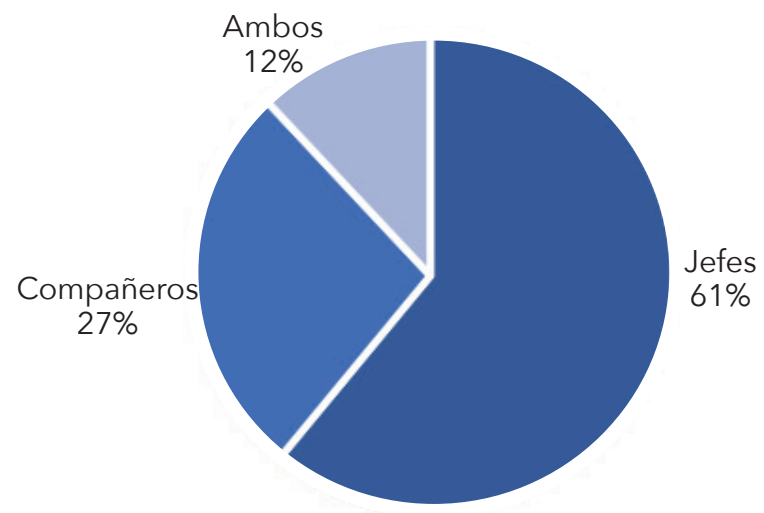

Fuente: elaboración propia con base en las encuestas.

De nuevo los jefes son los autores protagónicos del acoso. El mobbing se encuentra muy relacionado con el ejercicio del poder (Leymann, 1996), por lo que es más probable que cuando las relaciones laborales son asimétricas o desiguales, se presente con más frecuencia, ya que entre más alta sea la posición jerárquica del trabajador, más fácil será para éste desempeñar el papel del victimario. Foucault (2002 [1975]) señala que quienes tienen una posición de poder sobre otros, utilizan la violencia como medio para controlar, dominar y mantener el orden. Con el fin de explicar más a fondo la relación de la categoría de poder con el mobbing, López y Seco (2016) reflexionan sobre este fenómeno con base en la teoría de Bourdieu. Mencionan que muchas veces las técnicas de intimidación o prácticas de acoso por parte de los jefes hacia sus 
subordinados son invisibilizadas, justificadas e incluso apoyadas por las mismas organizaciones como acciones necesarias para disciplinar a su fuerza laboral, para aumentar la productividad o alcanzar algún otro objetivo dentro de la empresa. La producción en masa y los reducidos tiempos de entrega son algunas de las características de la IME. Por esa razón las exigencias de trabajo se llegan a tornar violentas. En las entrevistas semiestructuradas algunos operadores manifestaron estar expuestos a gritos, empujones e insultos de parte de sus supervisores. Ellos relataron lo siguiente:

Los supervisores se creen dioses. Nos gritan todo el tiempo, nos tratan muy mal y lo peor es que nadie les puede decir nada, porque si te quejas, la agarran contra ti y te va peor. (Operadora de 48 años)

A mí se la pasan gritándome todo el tiempo y así no se puede trabajar. (Operador de 21 años de edad)

Cuando trabajaba en [otra maquila], una vez le contesté a un supervisor, porque era muy grosero con todos, y yo ya estaba cansada de que fuera así. La verdad no lo hubiera hecho. Me dio más trabajo, me canceló los permisos, siempre me evaluaba mal y pues al final me terminaron despidiendo. (Operadora de 23 años)

Otra de las situaciones en la IME son las conductas de hostigamiento y acoso sexual a las operadoras de producción. En este rubro fue muy difícil obtener datos reales, ya que las trabajadoras se sentían incómodas al hablar de estos temas. Dos de ellas comentaron:

Aquí hay mucho acoso sexual por parte de los compañeros y de los jefes, sobre todo con las muchachas más jóvenes que entran a trabajar aquí. Yo siempre escucho que los compañeros siempre les están diciendo cosas, y también los supervisores, sólo que ellos son más sorderos [es decir, discretos]. A la salida las llaman y les dicen que si quieren privilegios deben salir con ellos. (Operadora de 54 años)

Sí hay mucho acoso, pero mis compañeras no le van a decir nada, les da vergüenza. (Operadora de 19 años)

En este nivel se manifestaron cada una de las 43 conductas de mobbing contenidas en el cuestionario. Entre las conductas más persistentes, se encuentran la exageración de errores (38\%), las restricciones de comunicación (37\%), no sentirse valorados, las críticas constantes, las provocaciones para sacarlos de quicio, la presión indebida, las acusaciones injustificadas, las restricciones de comunicación, el sentirse ignorados o excluidos y la asignación de tareas sin valor, entre otras (entre $25 \%$ y $30 \%$ ) (véase figura 6 ).

En uno de los apartados del cuestionario se preguntó a los trabajadores si conocían o habían escuchado hablar del término mobbing. La mayoría respondió de manera negativa. Los operadores y los técnicos de producción tuvieron el mayor porcentaje de desconocimiento de la palabra (89\%) (véase figura 7). 
Figura 6. Conductas de mobbing más frecuentes en el nivel operativo

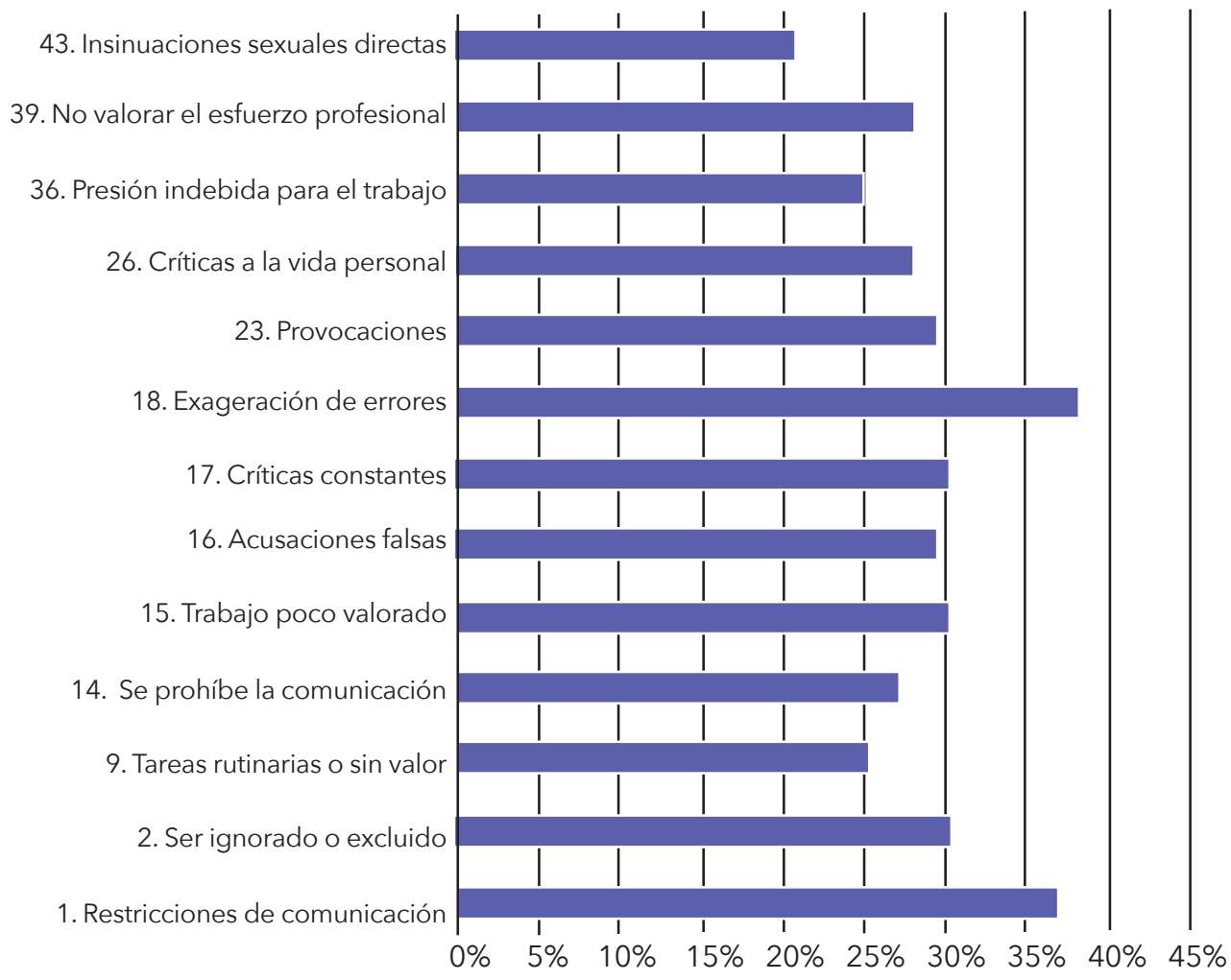

Fuente: elaboración propia con base en las encuestas.

\section{Figura 7. Conocimiento del término mobbing}

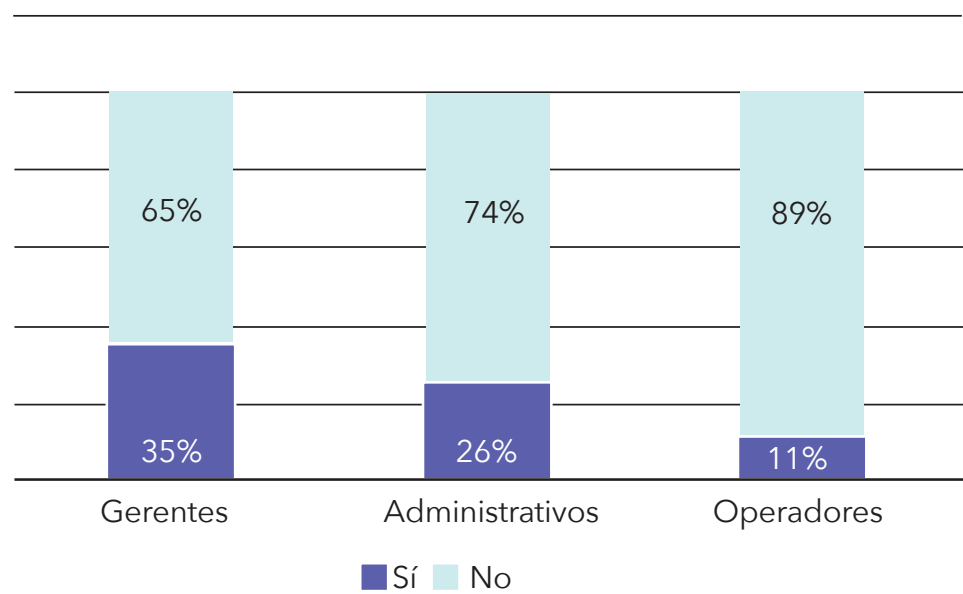

Fuente: elaboración propia con base en las encuestas. 
Mecanismos de apoyo dentro de la organización para las víctimas de mobbing

Otro de los cuestionamientos fue el siguiente: ¿existe algún tipo de apoyo eficaz en la organización para los trabajadores víctimas de mobbing? Con base en las respuestas de los trabajadores, se podría decir que no existe ningún mecanismo eficaz para contrarrestar esta conducta en sus centros de trabajo (véase figura 8).

Figura 8. Apoyo eficaz dentro de la organización para los trabajadores víctimas de mobbing

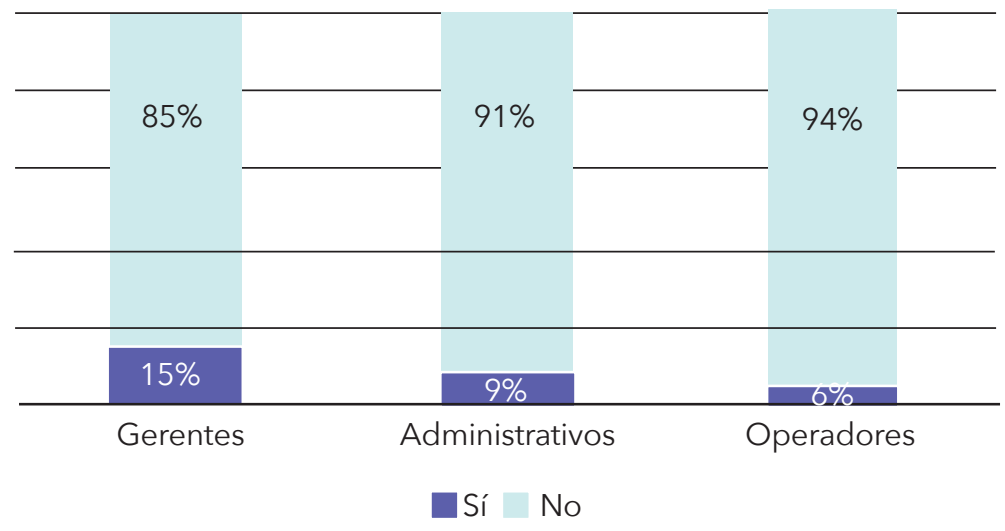

Fuente: elaboración propia con base en las encuestas.

La mayoría de los trabajadores externaron que el departamento de recursos humanos debería ser dicho mecanismo de defensa. Sin embargo, en algunas ocasiones es todo lo contrario. Algunos administradores relataron lo siguiente:

El departamento de Recursos Humanos está del lado de los jefes. Sí puedes ir a quejarte y te escuchan, pero la verdad nunca hacen nada. (Administrador de 31 años)

Una vez fui a quejarme con la encargada de Recursos Humanos por una situación de acoso por parte de mi jefe. Me dijo que no me preocupara, que ellos lo checaban. Al final no hicieron nada y el jefe siguió comportándose igual. (Administradora de 27años)

Algunos trabajadores se sienten indefensos ante las situaciones de mobbing, porque no hay apoyo de parte de la organización ni de las autoridades corres- 
pondientes, como la Secretaría del Trabajo (ST) a través de la Procuraduría Federal de la Defensa del Trabajo (PROFEDET):

En mi maquila fueron a dar una plática de acoso laboral, pero de qué sirve que sepamos del acoso si al final nadie hace nada. (Operador de 21 años)

Yo tengo una familia grande que depende de mi empleo. Si pongo una denuncia, lo más probable es que me terminen despidiendo y luego, cuando pidan referencias para contratarme en otro lado, la empresa anterior me etiqueta como trabajador conflictivo y así es más difícil. Mejor es quedarse callado y aguantarse. (Jefe de grupo de 24 años)

\section{Conclusiones y recomendaciones}

Con base en la revisión de la literatura, se puede concluir que el mobbing no es algo nuevo y que siempre ha estado presente en las organizaciones de trabajo. Sin embargo, su estudio y conceptualización tienen apenas unas cuantas décadas. Las diferentes conceptualizaciones del mobbing son los aportes más significativos en este campo, puesto que ahora los trabajadores que sufren daños a causa del acoso son capaces de identificar con exactitud que están siendo víctimas.

Respecto al objetivo central de la investigación, se logró determinar la prevalencia del mobbing en la IME en Ciudad Juárez. Resultó que de los 384 trabajadores encuestados, $47 \%$ fue víctima. La aplicación de la escala de Cisneros contribuyó en gran medida al logro de dicho objetivo. No obstante, sería pertinente en estudios futuros aplicar las dos escalas faltantes del barómetro de Cisneros para obtener información más detallada sobre los factores de riesgo, las causas y las consecuencias del acoso psicológico laboral; así como considerar una muestra más amplia de trabajadores que abarque todos los parques y zonas industriales de la ciudad. Tanto la escala como el barómetro de Cisneros son instrumentos validados en España, pero sería importante validarlos con trabajadores mexicanos para obtener resultados más confiables y significativos.

En lo que respecta al acoso, en el nivel operativo se presentaron los mayores porcentajes. Los operadores de producción se encuentran en el último peldaño de la jerarquía organizacional. Los salarios bajos, el trabajo manual y repetitivo, la carencia de autoridad y autonomía para la toma de decisiones los convierte en los trabajadores más vulnerables. Sobre las víctimas y los autores del acoso, los resultados arrojaron la presencia de mobbing en tres niveles: horizontal, o entre compañeros; vertical ascendente, es decir, de los subordinados hacia el jefe; y el vertical descendente, de los jefes hacia los subordinados (Lugo, 2017). Este último es el más frecuente. En esta investigación, los principales autores del acoso en los tres niveles de puestos, dada su posición de poder, son los jefes. 
En cuanto al sexo de las víctimas, se observó en todos los casos que las mujeres son quienes más sufren de acoso. Numerosos estudios han puesto de manifiesto que las mujeres son más violentadas que los hombres en sus espacios de trabajo (Leymann, 1996; Matud, Velasco, Sánchez, Espejo, Pino y Voltés, 2013; Piñuel, 2001; Scarone, 2014; Zúñiga, 2008). Tal y como menciona Zúñiga (2008): “la violencia afecta a hombres y mujeres, pero no de la misma manera" (p. 178). Las mujeres en la IME no son la excepción. García, Álvarez, Ramírez y Aranibar (2018) comentan:

La situación laboral en México en las maquiladoras se ha caracterizado por ser altamente agresiva para la mujer, en una cultura machista en la que la mujer sufre violencia verbal y psicológica, y muchas veces física y sexual, donde el jefe es inaccesible, al ignorarla o aprovecharse de su cargo para acosarla. (p. 74)

En México existen múltiples programas y campañas para prevenir y erradicar la violencia en contra de las mujeres en el ámbito laboral, pero aún hay intolerancia, discriminación, maltrato, descalificación y machismo en las organizaciones. Zúñiga (2008) menciona que "a pesar de la creciente participación de las mujeres, la esfera laboral continúa siendo territorio masculino, donde los hombres se desplazan con libertad, sin obstáculos que les coarten sus movimientos" (p. 185). Desde la contratación, y una vez dentro, los esquemas laborales en la IME, de oportunidades y de crecimiento profesional tienden a discriminar y a segregarlas (Scarone, 2014). Es el caso de $100 \%$ de las mujeres en puestos gerenciales, quienes manifestaron ser víctimas de mobbing por el solo hecho de ser mujeres.

Con respecto a la antigüedad en el trabajo, se puede concluir que entre más tiempo tengan los trabajadores laborando en la IME, más normalizan las situaciones de acoso, muchas de las cuales son percibidas como parte del ambiente laboral. La falta de atención a las condiciones y al ambiente de trabajo, así como a las ya mencionadas intensas cargas y ritmos acelerados de trabajo, pueden derivar en mobbing. Es preciso que las maquiladoras establezcan medidas y políticas organizacionales para prevenir esta conducta. También se debe contemplar el rediseño de una nueva estructura organizacional que permita la reducción de cargas absurdas de trabajo, así como formular y aplicar sanciones a los autores de mobbing. Una vez establecidas las medidas y las políticas organizacionales, se debe contar con un organismo encargado de dar seguimiento a dichas acciones. Como se pudo vislumbrar en los resultados obtenidos, en la actualidad la IME carece de mecanismos eficaces de apoyo a las víctimas. Se deben proporcionar los medios para que los trabajadores puedan denunciar las situaciones de acoso, ya sea a través del departamento de recursos humanos o de algún otro organismo interno, de modo que se canalicen según su gravedad hacia la autoridad correspondiente.

En cuanto a la intervención del Estado, a pesar de que en los últimos años se han logrado algunos avances importantes, como los mencionados en el análisis de los resultados, se deben redoblar esfuerzos para tipificar la figura del mob- 
bing de manera integral en México, puesto que todavía existen situaciones de acoso que aún no están contempladas por la ley.

Ya sea por la vía laboral, civil, administrativa o judicial son pocas las denuncias y demandas ante las instancias correspondientes, tales como el Ministerio Público o la Junta de Conciliación y Arbitraje, pues los trabajadores prefieren sufrir los daños causados por el acoso que someterse a un proceso legal interminable en contra del acosador o de la organización. La realidad es que no se aplican las sanciones existentes, ni a las organizaciones ni a los acosadores, porque en la mayoría de los casos las víctimas terminan abandonando la organización, ya sea de manera voluntaria o porque se les despide. Es responsabilidad de las organizaciones, del Estado y de la sociedad trabajar en conjunto para crear mecanismos más eficaces de defensa que garanticen el derecho del trabajador a un espacio laboral libre de violencia.

\section{Referencias}

Agervold, M. (2009). The significance of organizational factors for the incidence of bullying. Scandinavian Journal of Psychology, 50, 267-276.

Björkqvist, K., Österman, K., y Hjelt-Back, M. (1994). Aggression among university employees. Aggressive Behavior, 20, 173-184.

Carrillo, J. (2004). Principales estadísticas de la industria maquiladora. Encuesta sobre aprendizaje tecnológico y escalamiento industrial. Tijuana: El Colegio de la Frontera Norte.

Contreras, O., y Munguía, L. (2007). Evolución de las maquiladoras en México: política industrial y aprendizaje tecnológico. región y sociedad, 19(especial), 71-87. doi: 10.22198/rys.2007.0.a566

Einarsen, S., Hoel, H., Zapf, D., y Cooper, C. L. (2003). The concept of bullying at work: the European tradition. En S. Einarsen, H. Hoel, D. Zapf y C. L. Cooper (eds.), Bullying and Emotional Abuse in the Workplace. International Perspectives in Research and Practice (pp. 3-30). Londres: Taylor \& Francis.

Fidalgo, A., y Piñuel, I. (2004). La escala Cisneros como herramienta de valoración del mobbing. Revista Psicothema, 16(4), 615-624. Recuperado de http://www.psicothema.com/pdf/3041.pdf

Foucault, M. (2002). Vigilar y castigar. Nacimiento de la prisión. Recuperado de https: / /www.ivanillich.org.mx/Foucault-Castigar.pdf

Fuentes-Valdivieso, R. (2008). Mobbing o acoso psicológico laboral. Revista de Sanidad Militar, 62(2), 91-96. Recuperado de https://www.medigraphic. $\mathrm{com} / \mathrm{pdfs} / \mathrm{sanmil} / \mathrm{sm}-2008 / \mathrm{sm082f}$.pdf

García, B., Álvarez, M., Ramírez, M., y Aranibar, M. (2018). Acoso laboral a las mujeres en las maquiladoras, ¿mito o realidad? The Anáhuac Journal: Business and Economics, 18(1), 63-93.

González de Rivera, J. L., y Rodríguez-Abuín, M. (2003). Cuestionario de estrategias de acoso psicológico: el LIPT-60 (Leymann Inventory of Psychological Terrorization) en versión española. Psiquis, 24(2), 59-66. Recuperado de http://www.gonzalezderivera.com/art/pdf/manual-lipt60.pdf 
Hirigoyen, M. F. (1999). El acoso moral, el maltrato psicológico en la vida cotidiana. Barcelona: Paidós. Recuperado de http: //www.acosomoral.org/ EntrevGuevara.htm

Hirigoyen, M. F. (2001). El acoso moral en el trabajo. Distinguir lo verdadero de lo falso. Barcelona: Paidós.

Instituto Nacional de Estadística y Geografía (INEGI). (2019). Programa de la Industria Manufacturera, Maquiladora y de Servicios de Exportación (IMMEX). Recuperado de https://www.inegi.org.mx/programas/immex/default.html\#Tabulados

Larsson, A. (2016). La historia conceptual del “mobbing”. (Resúmenes de ponencia y de artículo, Sergio Navarrete, trad.). Recuperado de https:/ /www. researchgate.net/publication/299409398_La_Historia_Conceptual_del_Mobbing_-_2_resumenes

Leymann, H. (1992). Leymann Inventory of Psychological Terror. Violen: Karlskrona.

Leymann, H. (1996). Mobbing: la persécution au travail. París: Seuil.

López-Pino, C. M., y Seco, E. (2016). Tipología de mobbing - una mirada desde la responsabilidad de la empresa. Sociologias, 18(43), 364-401. doi: 10.1590/15174522-018004321

Lorenz, K. (1971). Sobre la agresión, el pretendido mal. Madrid: Siglo XXI Editores.

Lugo, M. (2017). Acoso laboral "mobbing”. Comisión Nacional de los Derechos Humanos. Recuperado de http://appweb.cndh.org.mx/biblioteca/archivos/ pdfs/Acoso-Laboral-Mobbing.pdf

Martín, F. , Pérez, J. , y López, J. (2002). El hostigamiento psicológico en el trabajo: Mobbing. Recuperado de https://www.insst.es/documents/94886/326962/ ntp_476.pdf/de8bdee0-e8f5-46c7-b4c0-1d0f62e9db69

Matud, A., Velasco, M., Sánchez, T., Espejo, L., Pino, M., y Voltes, D. (2013). Acoso laboral en mujeres y hombres: un estudio en la población española. Salud de los Trabajadores, 21(1), 19-30. Recuperado de http://ve.scielo.org / scielo.php?script=sci_arttext\&pid=S1315-01382013000100003\&ln$\mathrm{g}=\mathrm{es} \& \mathrm{t} \operatorname{lng}=\mathrm{es}$

Miguel, V. de, y Prieto, J. (2016). El acoso laboral como factor determinante en la productividad empresarial: el caso español. Perspectivas, 38, 25-44. Recuperado de https: / / www.redalyc.org/pdf/4259/425948032003.pdf

Morales, M. A. (2016). Aproximación al acoso laboral desde la legislación comparada. Boletín Mexicano de Derecho Comparado, 49(147), 71-98. Recuperado de http://www.scielo.org.mx/scielo.php?script=sci_arttext\&pi$\mathrm{d}=\mathrm{S} 0041-86332016000300071 \& \operatorname{lng}=e s \& t \operatorname{lng}=e \mathrm{~s}$

Pando, M. (octubre de 2011). Encuentro Internacional de Salud Ocupacional, Universidad de Guadalajara, México. Recuperado de http://www.udg.mx/ es/noticia/en-mexico-8-de-cada-10-trabajadores-han-sufrido-mobbing

Pando, M., Aranda, C., y Olivares, D. (2012). Análisis factorial confirmatorio del inventario de violencia y acoso psicológico en el trabajo (IVAPT-PANDO) para Bolivia y Ecuador. Liberabit, 18(1), 27-36. Recuperado de http://www.scielo.org.pe/scielo.php?script=sci_arttext\&pid=S1729-48272012000100004\&ln$\mathrm{g}=\mathrm{es} \& \mathrm{t} \operatorname{lng}=\mathrm{es}$ 
Pando, M., Aranda, C., Preciado, L., Franco, S., y Salazar, J. (2006). Validez y confiabilidad del inventario de violencia y acoso psicológico en el trabajo (IVAPT-Pando). Rev. Enseñanza e Investigación en Psicología, 11(2), 319- 332. Recuperado de https: / / www.redalyc.org/pdf/292/29211208.pdf

Peña, F., y Sánchez, S. (2007). El mobbing y su impacto en la salud. En M. Cívera y M. Herrera (comps.), Estudios de antropología biológica (pp. 824-845). Ciudad de México: Universidad Nacional Autónoma de México (UNAM), Instituto de Investigaciones Antropológicas.

Piñuel, I. (2001). Mobbing, cómo sobrevivir al acoso psicológico en el trabajo. Santander: Sal Terrae.

Piñuel, I. (2015). Evaluación psicológica del acoso psicológico en el trabajo o mobbing en España mediante el cuestionario Cisneros (tesis doctoral). Universidad Complutense de Madrid. Facultad de Psicología, Departamento de Personalidad, Evaluación y Tratamiento Psicológico, Psicología Diferencial y del Trabajo. Recuperada de https://eprints.ucm.es/33244

Piñuel, I., y Oñate, A. (2002). La incidencia del mobbing o acoso psicológico en el trabajo en España. Revista de Relaciones Laborales de la UPV, Lan Harremanak, 7(2), 35-62. Recuperado de https://dialnet.unirioja.es/servlet/ articulo?codigo $=640312$

Piñuel, I., y Oñate, A. (2004). Libro blanco. Los riesgos psicosociales en la administración. La incidencia del mobbing y el burnout en la Agencia Estatal de la Administración Tributaria (AEAT) y en la Intervención General de la Administración del Estado (IGAE). Recuperado de https: / /www.uv.es/igualtat/recursos/actuacio/El\%20informe\%20Cisneros.pdf

Sánchez, M., y Ambrosio, M. T. (2010). Acoso laboral contra la mujer en México (mobbing). Revista Latinoamericana de Derecho Social, 10, 457. Recuperado de https: / / www.redalyc.org/pdf/4296/429640265017.pdf

Sánchez, S., Ravelo, P., y Melgoza, J. (2015). Violencia en la ciudad, en el trabajo maquilador y la subjetividad de obreras y obreros en Ciudad Juárez. El Cotidiano, 191, 87-96. Recuperado de https://www.redalyc.org/ pdf/325/32538023010.pdf

Scarone, M. (2014). Violencia laboral intramuros. Hostigamiento sexual y otras formas de violencia sexual contra la mujer en las maquiladoras de Sonora y Baja California. región y sociedad, 4, 129-154. doi: 10.22198/rys.2014.0.a89

Secretaría del Trabajo y Previsión Social (STPS). (1992). Ley Federal del Trabajo. México, novena edición.

Secretaría del Trabajo y Previsión Social (STPS). (2018). Norma Oficial Mexicana, factores de riesgo psicosocial en el trabajo. Identificación, análisis y prevención. Diario Oficial de la Federación.

Vidal, M. (2006). El mobbing en el trabajo. Su problemática. Revista General Informática de Derecho. Recuperado de https: / / dialnet.unirioja.es/servlet/ articulo?codigo=2163193

Zapf, D., y Einersen, S. (eds.) (2001). Bullying in the workplace: recent trends in research and practice -an introduction. European Journal of Work and Organizational Psychology, 10(4), 369-373. doi: 10.1080/13594320143000807 
Zapf, D., Knorz, C., y Kulla, M. (1996). On the relationship between mobbing factors and job vontent. European Journal of Work and Organizational Psychology, 5(2), 215-239.

Zúñiga, M. (2008). Violencia en el trabajo. La cultura de la dominación de género. En Roberto Castro e Irene Cacique (eds.) Estudios sobre cultura, género y violencia contra las mujeres, (pp. 173-196). Cuernavaca: UNAM. Recuperado de http://biblioteca.clacso.edu.ar/Mexico/crim-unam/20100329121733/ Estudiossobreculturagenero.pdf 